\title{
Making the Best of Examination Feedback to Improve the Quality of Teaching
}

\author{
Jun WAN*, Yanhui SUN, and Xiaoyan DENG Affiliation \\ College of Environment and Safety Engineering, Qingdao University of Science and Technology \\ Qingdao 266042, China \\ e-mail:wanjundz@sohu.com
}

\begin{abstract}
Examination is an important component part in teaching and learning of colleges and universities. The examination results are important bases for checking the quality of instruction. The teachers should analyze the examination conditions conscientiously and give the feedbacks to the students in time so as to guide the teaching and promote the teaching levels and students' qualities in colleges and universities. In this paper, the analyses of the test information feedback of the environmental monitoring course of the environmental engineering students were made. And the important part in students' learning of information feedback and examination paper analysis were also clarified. All that may be play a teaching guidance to environmental monitoring course. The performing examination feedback through analysis of test paper and communication with students after examination could achieve positive effects. It can improve the quality of teaching, strengthen the teaching management, help students make clear of difficulties, foster the students' critical thinking and make the teachers rethink the teaching.
\end{abstract}

Keywords—environmental monitoring; examination feedback; quality of teaching; examination analysis; environmental engineering

\section{INTRODUCTION}

Examination is an important role in the whole process of teaching. It has the effect of feedback, evaluation and incentive in the teaching process, therefore it is a key step to supervise teaching quality. The process of collecting examination feedback is widely recognized as a central strategy for monitoring the quality and standards of teaching and learning in higher education. The feedback analysis of test are usually used in primary and secondary school education, but seldom used in university education. However, the role of feedback in higher education is also very important [1-3]. Complete test summary including the detailed examination paper analysis and timely examination feedback plays an important role for improving the teaching quality. We should find the problems of teaching and learning according to the test results, and feedback to students immediately. Meanwhile we can improve the teaching work by examining the teaching objective and the effect of teaching measurement

In this paper, the analyses of the test information feedback of the environmental monitoring course of the environmental engineering students were made. And the important part in students' learning of information feedback and examination paper analysis were also clarified. All that may play a teaching guidance to environmental monitoring course. At the same time, in order to improve their professional accomplishment, the teachers should pay more attention to improve students' interest in learning and make them happy. Paying more attention to the test feedback effect can effectively optimize the teaching effect and improve the quality of teaching.

\section{EASE OF USE}

\section{A. Structure of test}

Bloom R. S. came up with main classification cognitive field of educational objective taxology in 1956 (Table 1). This kind of level classification system was still widely used to prepare the testing paper for its effectiveness [4,5].

TABLE I. MAIN CLASSIFICATION COGNITIVE FIELD OF EDUCATIONAL OBJECTIVE TAXOLOGY

\begin{tabular}{|l|l|}
\hline Category & description of learning level \\
\hline know & The simple memories of the knowledge \\
\hline realize & The minimum phase of Understand \\
\hline adhibition & Using of concepts and principles in special circumstances \\
\hline analyse & understand the internal relations of things \\
\hline synthesize & Thinking back together for a new complete thought \\
\hline appraise & Give a judge based on the content of evidence \\
\hline
\end{tabular}




\section{B. Testing case}

The personnel of the testing: environmental engineering students. The result of the first group testing: the highest score is 92 , the lowest score is 29 and the average score is 74.4. The result of the second group testing: the highest score is 95 , the lowest score is 38 and the average score is 76.9. The distribution of testing grade was displayed in Figure 1 and 2.

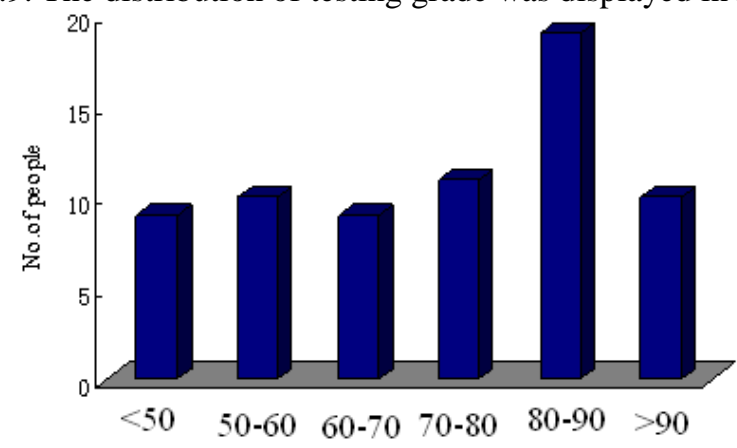

Fig. 1. The distribution of first group testing

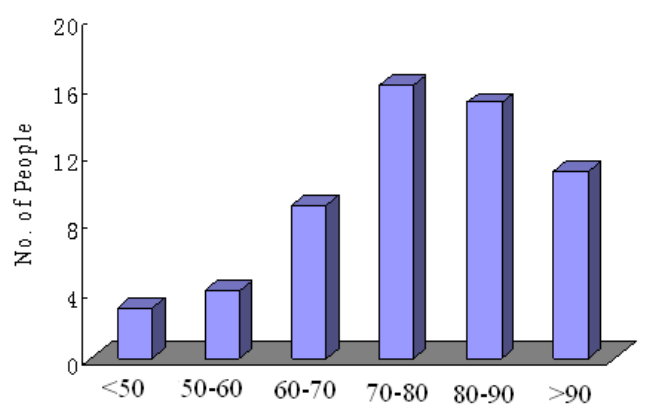

Fig. 2. The distribution of second group testing

\section{Analysis of testing paper}

The effectiveness, credibility, certain difficulty and distinction degree were required to every testing. Firstly, the degree of difficulty and discrimination should be appropriate. Generally speaking, the value range of the test difficulty should be discussed in the education statistics and geodesy. On the one hand, the proposition difficulty can't be too high and with no odd and tricky questions, in order to avoid low testing scores, which lead to undistinguishable between learning good and poor students. On the other hand, if the difficulty of the proposition is too low, it will make the test scores are generally high, and result in the discrimination is inconspicuous. In short, the proposition must be properly, otherwise, it will cause the test results distribution to skewed distribution. The examination of environmental monitoring is the self-designed test by our teachers, and it is quite different with the standardized test. The teacher's focus is the degree of the teaching goal that students could achieve, rather than the comparison of the individual difference among students. Therefore, we can't simply evaluate the difficulty of this examination according to the standards of metrology and statistics. As long as the subject reflects the teaching goal, questions are representative and belong to the content that students should master, we can also put these test questions into the examination even if they are much harder or easier. Of course, university course examinations also require a comparison among students to some extent. The test scores are able to distinguish students maximally. It is generally recognized that the difficulty coefficient of the test should be controlled in 0.6 to 0.85 is the most appropriate. How difficulty of the question is appropriate, and it will be determined by the type and nature of the examination. The difficulty value of any question is calculated on the basis of a certain test object, and its value depends on the selected sample groups. For the students of environmental engineering at this grade, there are four classes, and the total difficulty coefficient is 0.668 . From the total situation of examination, the difficulty coefficient of the first question is $\mathrm{P} 1=0.690$, and it mainly review the monitoring of water and wastewater. The difficulty coefficient of the second question is $\mathrm{P} 2=0.670$, and it primarily inspect the air pollution monitoring. The third question is the comprehensive shortanswer question, and it review other knowledge except water and atmosphere, the difficulty coefficient is P3 $=0.693$. The fourth question is the integrated design problem with $\mathrm{P} 4=0.633$. The common problem for students is the answer is not complete enough, and the students' comprehensive abilities should be improved. The fifth question is the integrated computation problem, and the difficulty coefficient is P5 $=0.665$. To be specific, most of the students can master these calculation questions better on water and atmosphere, but poor for the calculation problem on data statistics processing. 


\section{The information feedback of examination}

The analysis of test paper is greatly beneficial to ameliorate the teaching work, improve the quality of papers and questions, perfect the examination design, and do well in the future teaching and examination work [6]. At present, many teachers don't attach importance to the analysis of test paper. Teachers and teaching management department only focus on proposition, organizing examination, scoring, and submitting the examination results, while students only care about whether they could pass the exam, whether need a make-up exam, and whether can obtain the scholarship. Thus, it just put the score as the end of the examination work, without taking examination as an important means to get the teaching effect form the students' answers, and ignore the increase functions of the examination. Then the exam will not be a means but a purpose. It could increase the number of students' class response, improve the quality of class response and cultivate students' ability of critical thinking through the feedback function of examination. This has a certain effect on promoting the development of college students' critical ability. In addition, it not only requires a democratic atmosphere and harmonious environment, but also need teachers to encourage students to question boldly. The examination feedback analysis is undoubtedly a good method to cultivate and exercise students' critical thinking, and it could provide students an opportunity to show their ability to solve the problem.

\section{SUMMARY}

For the teachers themselves, they are able to timely collect real information from students in the process of examination feedback analysis. This is a rare precious wealth, and it is also a process of learning from students and relearning by themselves. By the analysis of examination feedback, teachers not only understand the students' learning demand and hope, know the problem that needed to be improved during the proposition, but also get a lot of enlightenment and inspiration from the teaching situations. Through the communication with students, it could promote the teachers' reflection of teaching, make teachers learn from selfreflection, enrich teaching experience in the reflection, and improve their teaching ability. From the perspective of teaching management, the process of organizing the examination feedback analysis is to check, reflect, summarize and promote both teaching and learning. It has accumulated valuable experience for the future teaching management, including proposition, examination, evaluation and so on. Meanwhile it provides teaching and learning an equal and sincere platform for communication and emotional interaction, and also plays a positive role in promoting both teachers and students.

Practice has proven that college students also have obvious demand for the teaching method of examination feedback analysis, and show a positive and cooperative attitude. The effect of this teaching method further illustrates the feedback, evaluation and incentive of teaching quality.

\section{ACKNOWLEDGMENT}

This research was financially supported by Qingdao University of Science and Technology of the excellent courses and excellent online courses

\section{REFERENCES}

[1] Liu Jing, Carry out scientific analysis of examination paper in time and give full play to the feedback function [J]. Journal of Xinjiang Medical University, 2006, 29(3): 278-280.

[2] Wang Mingli, To play the guiding role of examination and ensure the quality of personnel training [J]. Journal of Mudanjiang Normal University, 2008, 146(4): 98-99.

[3] Lei He, Zhang Yinling, Cao Baohua, Fu Jufang, Zhang Meixia, The practice of performing examination feedback to improve the quality of teaching [J], Journal of Nursing Administration, 2005, 5(2): 37-38.

[4] Dai Zhongheng, Education statistics, measurement and evaluation [M]. Beijing: China Science and Technology Press, $1990,152-154$.

[5] Dai Zhongheng, Psychology and education measurement [M]. Shanghai: East China Normal University Press, $1987,109$.

[6] Wang Yanli, Analysis and assessment of quality of college curricular examinations [J]. Journal of Beijing Union University (Natural Sciences), 2003, 17(4): 44-47 